Assessment of uncertain returns from investment in short rotation coppice using risk adjusted discount rates

\author{
Journal Article \\ Author(s): \\ Finger, Robert (1) \\ Publication date: \\ 2016-02 \\ Permanent link: \\ https://doi.org/10.3929/ethz-b-000108800 \\ Rights / license: \\ Creative Commons Attribution-NonCommercial-NoDerivatives 4.0 International \\ Originally published in: \\ Biomass and Bioenergy 85, https://doi.org/10.1016/j.biombioe.2015.12.028
}




\section{Postprint}

This is the accepted version of a paper published in Biomass and Bioenergy. This paper has been peer-reviewed but does not include the final publisher proof-corrections or journal pagination.

\section{Citation for the original published paper:}

Finger, R. (2016). Assessment of uncertain returns from investment in short rotation coppice using risk adjusted discount rates. Biomass and Bioenergy 85: 320-326. https://doi.org/10.1016/j.biombioe.2015.12.028

Access to the published version may require subscription.

N.B. When citing this work, cite the original published paper. 


\title{
Assessment of uncertain returns from investment in short rotation coppice using risk adjusted discount rates
}

\begin{abstract}
The increasing demand for renewable energy resources increases interest in the use of short rotation coppice (SRC) as alternative land use activity. The high uncertainty attached to returns from SRC is one of the key adoption barriers to farmers. One possibility to account for the role in investment assessments is the use of project specific risk adjusted discount rates (RADR). In this article, we revisit the theoretical background of RADR and illustrate different assumptions using an example of poplar based SRC. Time-invariant RADR used in the current literature on SRC assessment are found to overemphasize the role of risk for project assessment and usually give to little weights to returns in future periods, which are of particular relevance for long-term investments in SRC. Thus, the use of time invariant RADR is found to lead to biased recommendations towards the attractiveness of SRC and optimal policy support.
\end{abstract}

Keywords : SRC, investment, risk, perennial, bioenergy

\section{Introduction}

The increasing demand for renewable energy resources has triggered a significant interest to promote biomass production. Among other drivers, this increasing demand is caused by policy measures such as the target of the European Union that $20 \%$ of the total energy consumption come from renewable energy by 2020 [1]. Short rotation coppices (SRC) have been identified as an attractive option for production of biomass for bioenergy and material uses. SRC are characterized by high biomass yields in combination with highly extensive, low-input management. Due to little requirements for external nutrient supply and pesticide application and its positive effects on biodiversity, SRC is often perceived as more sustainable than other bioenergy crops such as rapeseed and maize $[2,3]$. Trees planted on agricultural land are usually harvested every two to five years. Due to the fact that nutrients are stored in root and stumps, a fast re-growth of shoots is ensured. The total lifetime for use of SRC is on average about twenty years, with values for the lifetime assumed in the literature ranging from eight to fifty years [2]. Tree species that are usually used in SRC in temperate regions are fast-growing and capable of stump sprouting, such as poplar (Populus spp.), willow (Salix spp.) and black locusts (Robinia spp.) [4]. Using SRC for renewable energy production represents a sector with enormous potential in terms of income for growers, the environment and the society at large $[5,6]$. 
However, the economic viability of SRC must be given that a relevant adoption can take place. To improve the economic attractiveness of SRC for farmers, various policy measures are in place. For instance, subsidization programs for have been established in Sweden and the UK [7,8]. Moreover, in the Greening component of the European Common Agricultural Policy (CAP), SRC can be accounted for as ecological focus area. Since 2015 links 30\% of the direct payments paid to farms to the requirement that, among other obligations, farms use at least $5 \%$ of their arable land as ecological focus area. These comprise, for instance, field margins, hedges, fallow land. SRC can be accounted here with a factor of 0.3. In contrast, other perennial bioenergy crops (e.g. non-tree species) such as Miscanthus have not been considered here. Thus, SRC has a comparative advantage and will potentially gain further significance. Note that in the past, the CAP allowed to count area under SRC as fallow land (see e.g. $[9,10])$.

Despite these support measures, the current uptake of SRC is still limited (e.g. about 5000 ha in Germany, 14000 ha in Sweden, 6000 ha in Italy, 7500 ha in the UK, [11]). The assessment of the economic viability is thus of highest importance to understand adoption barriers and designing appropriate policy measures (e.g. [12]). High opportunity costs and limited resource availability (e.g. concerning land) are important barriers for adoption. Moreover, the high uncertainty attached to returns from SRC is a key adoption barrier (e.g. $[2,9]$, which is particularly caused by the fact that revenues in distant future periods depend on (highly volatile) energy prices.

Hauk et al. [2] recently reviewed the literature on economic evaluation of short rotation coppice systems for energy biomass. It is largely acknowledged that cash flows from an investment in SRC are subject to a very high uncertainty, in particular due to high (energy) price volatility. Despite this fact, Hauk et al. [2] found only 3 out of 37 reviewed studies to consider risk if assessing the economic viability of an investment in SRC. Several approaches can be used to account for risks in investment projects (see [2] for an overview). For instance, Risk Analysis uses Monte Carlo simulations to derive a distribution of the target parameter (such as the NPV), based on which criteria such as stochastic dominance or stochastic efficiency with respect to a function can be applied to consider risk preferences. Moreover, Real Option Approaches can be used to account for the potential value of waiting (e.g. to invest in a SRC) due to uncertainty about future states. Here, considerations of risk aversion are not necessarily needed. Finally, expected utility approaches allow considering risk preferences of the decision maker. Here, also the uncertainty associated with a cash flow in a particular period and the risk preferences of the decision maker can be directly considered using risk adjusted discount rates (RADR).

Based on their review, Hauk et al. [2] recommend the use of adjusted discount rates to account for the uncertainty with respect to future costs and revenues from SRC. The use of RADR is 
recommended because it allows to directly consider both the level of uncertainty associated with the future cash flows from SRC as well as risk preferences of the decision maker if discounting future levels of expected cash flows (e.g. $[13,14,15])$. RADR allow considering project specific risks faced by farmers if making long-term investment decisions such as in short rotation coppice. Furthermore, risk adjusted discount rates are the primary way to consider risk aversion in real option analysis, which are frequently employed in recent economic assessments of perennial energy crops (see e.g. $[9,16,17,18,19])$. The use of RADR is also relevant for risk analysis in practice - for example, Bennouna et al. [20] report that about 77\% of surveyed Canadian firms employ RADR.

Despite this relevance, the use of RADR in SRC studies remains limited. Moreover, various studies make the simplifying assumptions of time-invariant RADR. That means, the same level of risk loadings is used to discount cash flows at any level of time (e.g. $[9,18,19,21])$. This assumption is motivated by the requirements for use of RADR in real option analysis applications in these papers. We argue that this is, however, only a theoretically valid assumption in a few rare cases. The potential consequences of this assumption with respect to policy conclusions have, however, not been discussed in the literature. Moreover, the specific choice of the RADR used is often based on standard sensitivity analysis, using simplifying assumptions and is thus not well motivated based on economic theory. Our hypothesis is that these assumptions made in the literature cause a misinterpretation of the role of risk for the profitability of SRC. Given the increasing focus on economic assessments of SRC (and other investment in risky perennial bioenergy crops), the correct incorporation and use of RADR is thus a central element for future research.

Based on this background, this paper aims to contribute to fill gaps in the literature as follows. First, we derive the theoretical background of RADR with a particular emphasis on the validity of time invariant RADR. Second, we aim to reveal policy implications of different assumptions on RADR usually made in SRC applications. To this end, a case study on an investment in SRC using poplar trees. Accordingly, the remainder of this paper is structured as follows. In the next section, we derive the theoretical basis for RADR and underline these will numerical examples. Subsequently, we introduce details on the case study and apply RADR in an SRC investment assessment. Finally, we discuss the obtained results and draw conclusions.

\section{The risk adjusted discount rate}

An uncertain level of cash flow, resulting from today's investment in SRC, occurring in period t is denoted $\tilde{X}_{t}$. An investor needs to be compensated in two ways to undertake the investment in SRC if future cash flows are uncertain: First, compensation with respect to the time value of money is 
required, i.e. using a risk free interest rate (reflecting secure foregone investment opportunities). Second, the project risk requires an additional compensation if the decision maker is risk averse.

Thus, the preferences of a decision maker for an uncertain future cash flow can be decomposed in a risk free interest rate $i$ and a risk loading $v$ (note that other papers also use the term risk premium here). The resulting RADR is defined as $R A D R=i+v$. Deriving the present value $P V_{0}$ for an uncertain cash flow in period $t$ with expected value $E\left(\tilde{X}_{t}\right)$ is thus:

$$
P V_{0}=\frac{E\left(\tilde{x}_{t}\right)}{(1+i+v)^{t}}
$$

The choice of $v$ reflects both the riskiness of the project and the risk preferences of the decision maker. Both higher risk and higher risk aversion should result in higher $v$. In contrast $v=0$ for risk neutral decision maker, so that standard (risk-free) discounting can be applied.

In the several of applications, the capital asset pricing model (CAPM) is the basis for determining the risk-adjusted rate (e.g. [15]). For considerations of risk aspects in SRC assessments this, however, has not been used in the literature (cp. e.g. [9]) because the consideration of individual risk preferences, risk perception and project specific changes of risks over time cannot be considered sufficiently (e.g. $[22,23]$, for similar arguments in timber applications). In contrast, an approach that focuses on the individual grower explicitly is chosen. To this end, the present value of an uncertain cash flow in period $t$ can be alternatively derived as follows:

$$
P V_{0}=\frac{C E_{t}}{(1+i)^{t}}
$$

where $C E_{t}$ is the certainty equivalent of the uncertain cash flow in $t . C E_{t}$ represents a sure amount of cash flow in period $t$ that is rated by the decision maker equivalently to the uncertain cash flows $\tilde{X}_{t}$. Because the numerator is now representing a riskless cash flow $\left(C E_{t}\right)$, no risk adjustment takes place in denominator, i.e. discounting is based on $i$ only. However, this assumption might be relaxed if there is some general risk to be considered in addition to the project specific risk reflected in $C E_{t}$ (see e.g. [24], for further details). We, however, will focus on the case where the entire risk is project specific and any additional (macro) risk is already reflected in the discount rate $i$. Risk averse decision makers are expected to be willing to give up parts of the expected level of cash flows to remove uncertainty, so that $C E_{t}<E\left(\tilde{X}_{t}\right)$. The difference $E\left(\tilde{X}_{t}\right)-C E_{t}=R P_{t}$ is the risk premium $R P_{t}$, indicating the implicit costs of risk, i.e. expresses the 'burden' of facing uncertainty in monetary terms. $R P_{t}$ thus also reflects the maximum willingness to pay to remove uncertainty from the cash flows in period t. Equation (2) may thus be rewritten as follows: 


$$
P V_{0}=\frac{E\left(\dot{x}_{t}\right)-R P_{t}}{(1+i)^{t}}
$$

Equations (1) and (3) now contain equivalent statements, i.e. both represent $P V_{0}$, the present value of the uncertain cash flow $\widetilde{X}_{t}$. Setting these equations to each other $\frac{E\left(\dot{X}_{t}\right)}{(1+i+v)^{t}}=\frac{E\left(\dot{X}_{t}\right)-R F}{(1+i)^{t}}$, allows us to derive an expression for $v$ :

$$
v=\frac{(1+i)}{\left(\frac{\left(E\left(\tilde{X}_{t}\right)-R P\right)}{\left(E\left(\tilde{X}_{t}\right)\right)}\right)^{1 / t}-(1+i)}
$$

For convenience of representation, we express the ratio of certainty equivalents to expected cash flow levels as follows: $\frac{\left(E\left(\tilde{X}_{t}\right)-R P\right)}{\left(E\left(\tilde{R}_{t}\right)\right)}=\frac{C E_{t}}{E\left(\tilde{R}_{t}\right)}=c$. Note risk neutrality, risk aversion and risk loving behavior (and cash flows being stochastic), imply $c=1, c<1$ and $c>1$, respectively. More general, $c$ is decreasing with increasing riskiness of the cash flow as well as increasing in the level of risk aversion of the decision maker. Equation (4) now can be rewritten as

$$
v=\frac{(1+i)}{c^{1 / t}}-(1+i)
$$

The risk loading increases with increasing project risk and risk aversion, so that it decreases in $c$ :

$$
\frac{\partial v}{\partial c}=-\frac{1}{t} \frac{(1+i)}{c \frac{1}{t}+1}<0
$$

Furthermore, we find the risk adjusted discount rate to decrease with time:

$$
\frac{\partial v}{\partial t}=(1+i) \ln (c) \cdot c^{-\frac{1}{t}} \cdot\left(+\frac{1}{t^{2}}\right)<0
$$

Note that we focus on a risk averse decision maker, i.e. $c<1$ so that $\ln (c)<0$. Thus, the further the uncertain cash flow, ceteris paribus, occurs; the lower has to be the adjustments to account for risk and risk aversion. Due to the compound interest effect, the present values of uncertain future cash flows are nevertheless reduced.

In Table 1, some numerical examples with relevant time spans for SRC are presented (see [23], for further numerical examples). For different levels of $c$ and $t$, values of $v$ (in \%, i.e. $v \cdot 100$ ) are presented. Furthermore, calculations are given for two levels of riskless interest rates, i.e. $i=0.01$ and $i=0.05$. The left columns represent low levels of $c$, corresponding to very low relative levels of certainty equivalents $\left(C E_{t}\right)$ or equivalently, extremely large levels of risk premiums $\left(R P_{t}\right)$. For these situations, the levels of $v$ are very high. However, these situations would reflect situations containing 
extremely high risks, which are not likely to be encountered in practice. For example, extremely high risks (low levels of $c$ ) are usually not applicable for nearby periods (low levels of $t$ ). The last column represents the case of risk neutrality, with $v$ being zero as discussed above. We find values of $v$ to decrease sharply with $t$, e.g. comparing $v=11.22$ for $\mathrm{c}=0.9$ and $t=1$ with $v=0.53$ for $\mathrm{c}=0.9$ and $t=20$. A transfer from high RADR, that have been derived for short time spans, also for uncertain cash flows in faraway periods would dramatically overemphasize the relevance of risk. This finding contrasts the above mentioned common practice to use a single RADR (or a single risk loading) over the entire range of SRC lifetime. Moreover, it shows that an increasing level of the riskless discount rate, ceteris paribus, reduces the levels of $v$. However, this reduction is small if compared with its sensitivity to changes in $c$ and $t$.

<Table 1. Risk loading $v$ for different combinations of $c, i$ and $t$. >

Resulting from equation (5), an individual discount rate for every year is necessary (a specific RADR needs to be calculated), even if the riskiness of the cash flows and risk attitude of the decision maker do not change with time. Conceptually, this assumption of constant risk preferences and RADR is furthermore difficult to defend as levels of wealth may fluctuate over time but influence risk aversion as decreasing absolute risk aversion is a common observation made in practice [25]. This contrasts, however, the current use of RADR (or risk loadings) in the (rare) literature on economic assessments of SRC that accounts for risks.

Using different literature search engines such as 'Scopus ${ }^{\circledR \prime}$ and 'scholar.google' and focussing on combinations of terms such as 'short rotation', 'SRC' and 'risk adjusted discount', 'RADR' etc., only four peer-reviewed papers on SRC adoption could be identified that employ risk adjusted discount rates (even though enormous amounts of papers apply discounting in SRC applications, see e.g. [2,6], for overviews). Among those four studies, Musshoff [9] uses time invariant rates for the risk loading $v$ equal to $5 \%$ and 10\%. Di Corato et al. [21] follow Musshoff [9] and assume risk loadings of 5\% and $10 \%$ in sensitivity analyses. These values are not chosen based on project specific risks or assumptions on risk preferences of SRC growers. This reflects the more general approach to consider sensitivity analyses with respect to RADR (or risk loadings) in agricultural investment applications (e.g. $[26,27])$. The levels of risk loadings considered in these sensitivity analyses range from $0 \%$ to $12 \%$.

The levels of risk loadings considered in these sensitivity analyses range from $0 \%$ to $12 \%$. WolbertHaverkamp and Musshoff $[18,19]$ use time invariant rates, but risk loadings differ according to the levels of the expected level of gross margins or the level of risk aversion. The considered time horizon to assess the RADR is in both papers one period, i.e. the RADR derived for $t=1$ is used for all 
considered periods. The levels of $v$ derived in these papers range from 0.49 to 3.77 and from 0.77 to 3.99. The use of this simplified assumption is motivated by the requirement chose a single level of RADR in real option analysis applications underlying the above mentioned papers. This choice is needed, because describing risk and respective RADR depending on choices made within the time horizon considered would result in an 'intractable exercise' [14]. The choice of the RADR remains thus a compromise.

But, the use of time-invariant risk loadings might also be defendable in the theoretical framework presented above. More specifically, if the uncertainty associated with future cash flows increases with increasing distance from the present period with constant (growth) rates. Assuming that $c$ decreases (i.e., that the relative risk premium increases) at a constant rate over time, such as:

$$
c_{t}=(1-d)^{t},
$$

equation (5) simplifies to:

(9)

$$
v=\frac{(1+i)}{(1-d)}-(1+i)
$$

Equation (9) shows that the resulting level of $v$ is not any longer dependent on the time $t$. Thus, a single RADR can be used throughout the entire periods in which cash flows have to be discounted to current periods. Table 2 presents some numerical examples showing the levels of $v$ (in \%, i.e. $v \cdot 100$ ) in relation to the levels of $d$ and $i$. Even for high levels of $d$ and $i$, the levels of $v$ are in moderate ranges.

\section{$<$ Table 2. Risk loading $v$ for different levels of $i$ and $d$. >}

The implications of choosing a specific level of $d$ for the development of $c$, i.e. the ratio of the certainty equivalent and the expected level of cash flow is visualized in Figure 1, that presents the levels $c$ for different values for $d$ and t. It shows that assuming a level of $d$ of 0.1 implies that the level of $c$ in period $t=20$ is equal to 0.12 . Even for small values of $d$, e.g. 0.03 , the level of $c$ in period $t=20$ is low (0.54), indicating very large risk premiums associated with future cash flows.

This assumption of sharp but saturating increases in project risk for future periods might be a reasonable assumption for SRC applications because the uncertainty attached to output prices is increasing for future periods. However, the use of time-invariant RADR requires $c$ (the ratio of certainty equivalent and expected payout) to decrease over time at a constant rate. The subsequent section uses an illustrating example on a SRC project to explore the validity of this assumption. 


\section{Illustrating example}

In order to illustrate the effect of time varying RADR in SRC applications, we re-investigate a SRC investment problem based on poplar trees, initially described by Musshoff [9]. We do not consider the real option analysis conducted by Musshoff [9] but aim to focus on a simplified and clear example for illustration purposes. We have chosen this example as it allows to focus presentation of implications of different strategies to consider risk adjusted discount rates.

This remainder of this section is structured as follows. First, we introduce the basic characteristics of the example. Second, the stochastic price process used is introduced. Third, net margin distributions and resulting outcomes for the risk premium are presented. Fourth, risk loadings, RADR and NPV calculations are derived for different levels of risk aversion and compared with standard assumptions.

In the here used example, Musshoff [9] assumes SRC to be cultivated on fallow land. Thus, there are no opportunity costs, i.e. SRC is not replacing any crop, and no direct payments received. Furthermore, [9] considered a useful lifetime of SRC of 30 years, with a rotation period of 5 years, i.e. 6 harvest events. Note that a total lifetime above twenty years would actually imply the consideration of this plantation as forest (instead of crop land) and thus non-eligibility for direct payments in Germany [28]. The final products considered here are wood chips, which are used for heating. Musshoff [9] did not consider any costs apart from i) planting (2875€ ha $\left.{ }^{-1}\right)$, ii) harvesting, drying and transportation (24€ $\mathrm{t}^{-1}$ of DM) and iii) recultivation (1400€ ha-1). The first harvest (at $\left.t=5\right)$ results in a yield of $25 \mathrm{t} \mathrm{DM}$, and all subsequent harvesting events allow to harvest $40 \mathrm{t} D M$.

Stochastic price process. Musshoff [9] discusses different possibilities how to consider the volatility of wood chip prices. Yield variability is not considered in the here used example, but should be addressed in future research. One important characteristic is that uncertainty regarding these prices increases with future periods. Considering Brownian motions for price building processes allows to account for this property. More specifically, a Ornstein-Uhlenbeck (OU) Process is used to describe the stochastic price process. The OU process is based on the assumption that the process is mean reverting, i.e. prices tend to return to some long-run equilibrium. This assumption is particularly valid if prices for raw commodities are considered, where marginal costs may serve as long-run reference point for prices [30]. We define $x_{t}=\ln \left(P_{t}\right)$, with $P_{t}$ being woodchip price in period $\mathrm{t}$, marginal changes in logarithms of prices are described as $d x=\eta(\bar{x}-x) d t+\sigma d z_{t}$, where $\bar{x}$ is the 'normal' 
level of $x$ where it returns to and $\eta$ indicates the 'speed' of the reversion. Moreover, $\sigma$ is the standard deviation and $z_{t}$ is a Wiener process that follows a normal distribution $N(0, t)$. Given the Brownian motion nature of $d z_{t}$, we know that this percentage change is normally distributed. However, in contrast to a GBM process, the changes in $x$ are now dependent on the difference of $\bar{x}$ and $x$, so that the increments from one period to another are not fully independent (even though they have Markov properties). The expected values for $x_{t}$ are $E\left(x_{t}\right)=x_{0} e^{-\eta t}+\bar{x}\left(1-e^{-\eta t}\right)$ and the variance of $x_{t}$ is defined as $\operatorname{Var}\left(x_{t}\right)=\left(1-e^{-2 \eta t}\right) \frac{\sigma^{2}}{2 \eta}$. The resulting values for expected values and variance for woodchip prices are thus $E\left(P_{t}\right)=e^{E\left(x_{t}\right)+0.5 \operatorname{Var}\left(x_{t}\right)}$ and $\operatorname{Var}\left(P_{t}\right)=e^{2 E\left(x_{t}\right)+\operatorname{Var}\left(x_{t}\right)}\left(e^{\operatorname{Var}\left(x_{t}\right)}-1\right)$. Musshoff [9] estimates the following specifications for the OU process: $\bar{x}=3.92, \eta=0.22$ and $\sigma=0.22$. Moreover, $P_{0}$ is reported as $62.76 € \mathrm{t}^{-1}$ of $\mathrm{DM}([9], \mathrm{p} .81)$, so that the initial price is higher than the long-term average $e^{(\bar{x})}$ and expected prices will thus decrease with increasing $\mathrm{t}$ and converge to about $53 € \mathrm{t}^{-1}$ of $\mathrm{DM}$.

Net-margin distribution and risk premium. Based on the information given above, we can infer to the distribution of net-margins. These net margins account for revenues and costs in harvest periods $t=5$, $10,15,20,25,30$ as $\pi_{t}=P_{t} Y-Y C_{H}$, where $C_{H}$ represent the harvest costs that depend on the biomass yield harvested in period $t$, which is assumed to be deterministic. Thus, the expected net margins are $E\left(\pi_{t}\right)=E\left(P_{t}\right) Y-Y C_{H}$ and the variance of net margins is $\operatorname{Var}\left(\pi_{t}\right)=\operatorname{Var}\left(P_{t}\right) Y^{2}$. In period $t=30$, also re-cultivation costs $C_{R C}$ have to be considered such that $\pi_{30}=P_{30} Y-Y C_{H}-C_{R C}$. In period $t=0$, only cultivation costs $C_{C}$ occur.

Based on the information provided above, we can derive expected values and variances of netmargins for the relevant periods, which are presented in Table 3. Note that even though price levels follow a downward trend, the expected net-margin increases from period 5 to period 10 due to the yield increase (from $25 \mathrm{t} \mathrm{ha}^{-1}$ to $40 \mathrm{tha}^{-1}$ ).

\section{$<$ Table 3. Characteristics of cash flow distributions and risk premia $\left(\right.$ in $\left.€ \mathrm{ha}^{-1}\right)>$}

Focusing on the first two moments of the distributions of net-margins, we can approximate the risk premium RP as follows: $R P_{t} \approx 0.5 r \operatorname{Var}\left(\pi_{t}\right)$, where $r$ is the Arrow Pratt absolute coefficient of risk aversion (see [25]). We use four levels of absolute risk aversion to consider a wide range of preferences to risk. More specifically, we consider values for the Arrow Pratt absolute coefficient of risk aversion equal to i) 0 , ii) 0.001 , iii) 0.002 and iv) 0.003 (see e.g. [31,32], for similar sensitivity analysis and overviews on observed levels of risk aversion). 
The resulting values for c, i.e. $\frac{E\left(\pi_{t}\right)-R P}{E\left(\pi_{t}\right)}=c$, are presented in Table 4. For the risk neutral decisions maker $(r=0), c$ is equal to 1 in all periods. The values of $c$ range between 0.77 and 0.89 for $r=0.001$, between 0.55 and 0.78 for $r=0.002$ and between 0.33 and 0.67 for $r=0.003$. Moreover, the levels of $c$ are decreasing with increasing $t$, reflecting the increasing uncertainty regarding output prices. The decreases in the level of $c$ over time with saturating effects indicate that an approximation via time invariant risk loadings might indeed be reasonable (cp. Figure 1). As a particularity of our specific example, we find the values for $c$ in period $t=30$ to be larger than 1 due to the fact that $E\left(\pi_{t=30}\right)$ is negative.

\section{$<$ Table 4. Levels of $c$ for different degrees of risk aversion. $>$}

Risk loading, RADR and NPV calculation. Next, the levels of the risk loading are calculated as $v=\frac{(1+i)}{c^{1 / t}}-(1+i)$. Following [9], we use $i=0.0387$ as risk free interest rate. In Table 5, the calculated risk loadings are presented (in \%). We find $v$ to decrease with increasing $t$, expect for the step from $t=5$ to $t=10$, even though risks are increasing. Thus, the consideration of a constant level of $v$ over all periods can be rejected. We find the values of $v$ to be negative for $t=30$. One implication of negative uncertain future cash flows (and resulting values of $c$ larger than 1 ) is for example that even negative discount rates can occur from the here used formulas, i.e. that the decision maker is willing to pay a higher than the expected value to avoid uncertain costs (losses) in the future (see e.g. [33]). In terms of discounting, future negative uncertain cash flows are from today's perspective valued stronger than positive cash flows, thus $(i+v)$ becomes smaller. See e.g. [34] for further discussions on this property of the RADR approach and the high sensitivity to the assumptions made. Comparing the here identified levels of the risk loading with the hypothetical development for time invariant risk loadings presented in Table 2, we find numerical values to be in similar ranges, however, with sharp differences for later periods. But, also note that if the focus of the first period with risky returns would be one period 1 instead of period 5 , the risk loading would be substantially higher than the ones used in sensitivity analysis (and an unsuitable assumption to depict the real RADR). However, such differences in periods far away from $t=0$ are of lower relevance as they are down-weighted heavily in any case.

\section{<Table 5. Levels of the risk loading $v$ (in \%) for different degrees of risk aversion.>}

Based on the components presented above, we calculate the sum of expected cash flows that are discounted taking the risk loading presented in Table 5 and $i$ being equal to 3.87\% (Table 6). We find NPVs to be negative, independent of the consideration of risk aversion. Thus, we may interpret the 
derived NPVs as required subsidy level that has to be paid to farmers allowing them to cover parts of the establishment costs in period 0.

We find that the effect of considering risk (via RADR) has extremely strong effects on the evaluation of SRC projects. More specifically, the NPV decreases by about 610, 1260 and $1910 €$ ha $^{-1}$ if the level of absolute risk aversion increases from 0 to $0.001,0.002$ and 0.003 , respectively. Expressed in terms of the percentage of establishment costs that need to be compensated to the decision maker to make her indifferent between SRC investment and non-investment, we find these to be $8 \%, 29 \%$, $52 \%$ and $75 \%$ for the four levels of risk aversion considered. Thus, even slightly risk averse decision makers require substantially higher incentives in form of higher subsidies or a higher output price than if risk neutrality is assumed. Based on this finding, the little share of the current literature on economic assessments of SRC that accounts for risks [2] reveals a significant research gap.

Comparing the results between correctly derived time varying RADR and ad-hoc chosen time invariant RADR shows that final values of the NPV are in similar dimensions - even though the individual discounted cash flows differ substantially. In contrast to the case of time varying RADR, the last periods have almost no weight for the NPV if using time invariant RADR. Comparing the levels of the NPV, we find that this normal range of levels of absolute risk aversion [31] corresponds well to the 'ad-hoc' chosen levels of time invariant risk loadings between 0 and $10 \%$. But, note that this comes to the correct results for the wrong reasons. The too high down-weighting of distant positive cash flows is outweighed with a too high down-weighting of negative cash flows in the last period.

\section{$<$ Table 6. Discounted cash flows and NPVs (in $€$ ha $^{-1}$ ) for different levels of risk aversion.>}

\section{Conclusions}

We find time invariant levels of risk loadings to discount rates and thus time-invariant RADR only to be a valid assumption in very rare cases. This contrasts the assumptions usually made in the literature on the economic assessment of short rotation coppice, where risk loadings are time invariant and often based on ad-hoc chosen assumptions. We show that this approach overemphasizes the role of risk, in particular for future periods. However, using a numerical example for SRC based on poplar trees and applying RADR based on ad-hoc assumptions and exact time-variant calculations, we find that the levels of the NPV based on standard sensitivity analysis values (i.e. levels of $0-10 \%$ ) are not significantly different from 'correct' levels of NPVs. But, the simplified approach to RADR seems to be correct for the wrong reasons. In particular, cash flows in future periods are heavily underestimated if using time invariant RADR, overestimating the role of future risks. As a result, long term pay-outs, which are actually relevant for investments in biomass production using perennial energy crops, are not accounted for to the required extent. This also 
implies that the assessment of policies with implications for future periods, e.g. to ensure long-term support in form of annual payments, annual reductions of opportunity costs (such as in the Greening component of the (AP), or subsidies to recultivation costs would be significantly biased. Thus, the use of (any kind of) time invariant RADR will favour policy measures that are characterized by payments made early in the life-cycle, e.g. subsidies to establishment costs. This might however, not be the most efficient set of support measures from policy makers' perspectives. In conclusion, the use of time-invariant RADR in extension and policy analysis will cause recommendations on SRC adoption and policy design, respectively, that are not optimal for both farmers and policy makers. Thus, much more emphasis should be given to the time-variant representation of RADR. Future research should also account for the fact that the use of RADR in the assessment of SRC projects is limited as the approach presented does not distinguish up- and downside risks. Thus, a framework to particularly capture the role of downside risks might be required, as these are of high relevance for bioenergy crops and forestry applications (e.g. $[2,35])$.

\section{References}

[1] S. Jacobsson, A. Bergek, D. Finon, V. Lauber, C. Mitchell, D. Toke, A. Verbruggen, EU renewable energy support policy: Faith or facts?. Energy Policy 37(6) (2009) 2143-2146.

[2] S. Hauk, T. Knoke, S. Wittkopf, Economic evaluation of short rotation coppice systems for energy from biomass-a review. Renew Sust Energy Rev 29 (2014) 435-448.

[3] R.L. Rowe, N.R. Street, G. Taylor, Identifying potential environmental impacts of large-scale deployment of dedicated bioenergy crops in the UK. Renew Sust Energy Rev 13(1) (2009) 271-290.

[4] C. Aust, J. Schweier, F. Brodbeck, U.H. Sauter, G. Becker, J.P. Schnitzler, Land availability and potential biomass production with poplar and willow short rotation coppices in Germany. GCB Bioenerg 6(5) (2014) 521-533.

[5] A. Monti, S. Fazio, G. Venturi, Cradle-to-farm gate life cycle assessment in perennial energy crops. Eur J Agron 31(2) (2009) 77-84.

[6] R.J. Faasch, G. Patenaude, The economics of short rotation coppice in Germany. Biomass Bioenerg 45 (2012) 27-40.

[7] C. Mitchell, P. Connor, Renewable energy policy in the UK 1990-2003. Energy Policy 32(17) (2004) 1935-1947.

[8] B. Mola-Yudego, P. Pelkonen, The effects of policy incentives in the adoption of willow short rotation coppice for bioenergy in Sweden. Energy Policy 36(8) (2008) 3062-3068.

[9] O. Musshoff, Growing short rotation coppice on agricultural land in Germany: a real options approach. Biomass Bioenerg 41 (2012) 73-85. 
[10]C.P. Witzel, R. Finger, R., Economic evaluation of Miscanthus production - A review. Renewable \& Sustainable Energy Reviews 53 (2016) 681-696.

[11] H. Langeveld, F. Quist-Wessel, I. Dimitriou, P. Aronsson, C. Baum, U. Schulz, A. Bolte, S. Baum, J. Köhn, M. Weih, H. Gruss, P. Leinweber, N. Lamersdorf , P. Schmidt-Walter , G. Berndes, Assessing environmental impacts of short rotation coppice (SRC) expansion: model definition and preliminary results. Bioenergy Res 5(3) (2012)621-635.

[12] G.C. Van Kooten, S.L. Shaikh, P. Suchánek, Mitigating climate change by planting trees: the transaction costs trap. Land Econ 78(4) (2002) 559-572.

[13] E.F. Fama, Risk-adjusted discount rates and capital budgeting under uncertainty. J Financ Econ, 5(1) (1977) 3-24.

[14]M. Samis, G.A. Davis, D. Laughton, R. Poulin, Valuing uncertain asset cash flows when there are no options: A real options approach. Resour Policy 30(4) (2005) 285-298.

[15] M. Sand $\varnothing y$, T. Aven, D. Ford, On integrating risk perspectives in project management. Risk Mana (2005) 7-21.

[16] F. Song, J. Zhao, S.M. Swinton, Switching to perennial energy crops under uncertainty and costly reversibility. Am J Agric Econ 93(3) (2011) 768-783.

[17] F. Bartolini, D. Viaggi, An analysis of policy scenario effects on the adoption of energy production on the farm: A case study in Emilia-Romagna (Italy). Energy Policy 51 (2012) 454-464.

[18] M. Wolbert-Haverkamp, O. Musshoff, Is short rotation coppice economically interesting? An application to Germany. Agroforestry Syst 88(3) (2014) 413-426.

[19] M. Wolbert-Haverkamp, O. Musshoff, Are short rotation coppices an economically interesting form of land use? A real options analysis. Land Use Policy 38 (2014) 163-174.

[20] K. Bennouna, G.G. Meredith, T. Marchant, Improved capital budgeting decision making: evidence from Canada. Manag Decis 48(2) (2010) 225-247.

[21] L. Di Corato, A. Gazheli, C.J. Lagerkvist, Investing in energy forestry under uncertainty. Forest Policy Econ 34 (2013) 56-64.

[22] R.P. Khajuria, S. Kant, S. Laaksonen-Craig, Valuation of timber harvesting options using a contingent claims approach. Land Econ 85(4) (2009) 655-674.

[23] W.D. Klemperer, J.F. Cathcart, T. Häring, R.J. Alig, Risk and the discount rate in forestry. Can J Forest Res 24(2) (1994) 390-397.

[24] R. Obermaier, Risk analysis in investment appraisal based on the Monte Carlo simulation technique by A. Hacura, M. Jadamus-Hacura and A. Kocot. Eur Phys J B 30(3) (2002) 407-409.

[25] J.P. Chavas, Risk Analysis in Theory and Practice. New York: Elsevier (2004).

[26] J. M. Cozzolino, Controlling risk in capital budgeting: a practical use of utility theory for measurement and control of petroleum exploration risk. Eng Econ 25(3) (1979) 161-186. 
[27] T.G. Gebremedhin, S. Gebrelul, An investment analysis of meat goat enterprises for small-scale producers. Rev Agric Econ 14(1) (1992) 45-53.

[28] M. Bärwolff, H. Hansen, M.Hofmann, F. Setzer, Energieholz aus der Landwirtschaft. Fachagentur Nachwachsende Rohstoffe e.V. (FNR) (2012)

https://mediathek.fnr.de/broschuren/bioenergie/energiepflanzen/energieholz-aus-derlandwirtschaft.html, last accessed June 28, 2015.

[29] S. Hauk, S. Wittkopf, T. Knoke, Analysis of commercial short rotation coppices in Bavaria, southern Germany. Biomass Bioenerg 67 (2014) 401-412.

[30] A. K. Dixit, R.S. Pindyck, Investment under uncertainty. Princeton University Press, Princeton (1994).

[31] J.B. Hardaker, R.B.M. Huirne, J.R. Anderson, Coping with Risk in Agriculture. CAB International, New York (1997).

[32] C. Gardebroek, Comparing risk attitudes of organic and non-organic farmers with a Bayesian random coefficient model. Eur Rev Agric Econ 33(4) (2006) 485-510.

[33] R.H. Berry, R.G. Dyson, On the negative risk premium for risk adjusted discount rates. J Bus Fin Account 7(3) (1980) 427-436.

[34] T.J. Gallagher, J.K. Zumwalt, Risk-Adjusted Discount Rates Revisited. Fin Rev 26(1) (1991) 105114.

[35] P. Hildebrandt, T. Knoke, Investment decisions under uncertainty-A methodological review on forest science studies. Forest Policy Econ 13 (2011) 1-15. 
Figure 1. Levels of $\mathrm{c}$ for different assumptions on $d$ and $t$.

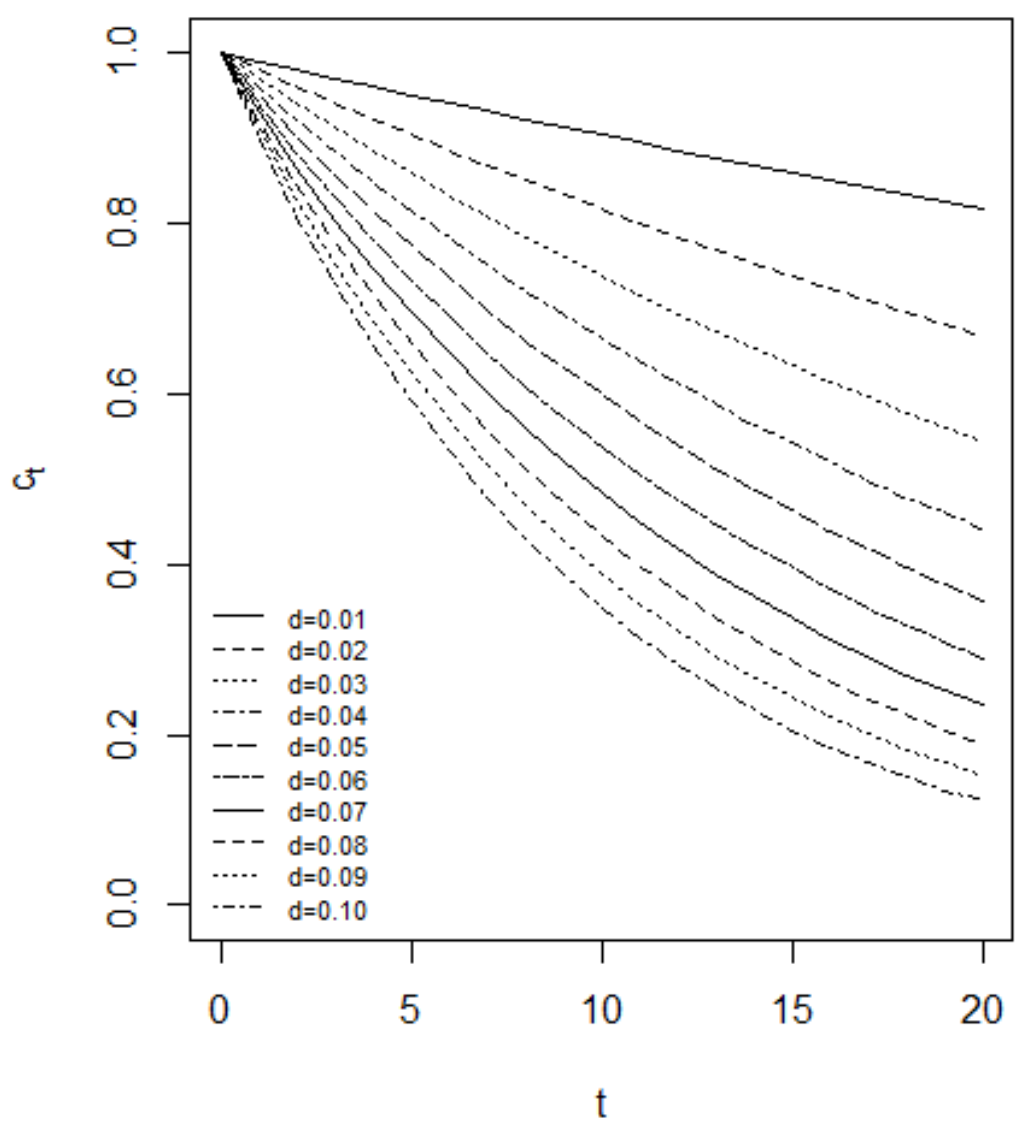

Note that $d$ is the (negative) annual growth rate of $c$, the ratio of certainty equivalents over expected cash flows (see equation 9) and t represents years. 
Table 1. Risk loading $v$ for different combinations of $c, i$ and $t$.

\begin{tabular}{llllllllllll}
\hline $\boldsymbol{i = 0 . 0 1}$ & & & \multicolumn{9}{c}{$\boldsymbol{c}$} \\
$\mathbf{t}$ & $\mathbf{0 . 1}$ & $\mathbf{0 . 2}$ & $\mathbf{0 . 3}$ & $\mathbf{0 . 4}$ & $\mathbf{0 . 5}$ & $\mathbf{0 . 6}$ & $\mathbf{0 . 7}$ & $\mathbf{0 . 8}$ & $\mathbf{0 . 9}$ & $\mathbf{1}$ \\
$\mathbf{1}$ & 909 & 404 & 235.67 & 151.50 & 101 & 67.33 & 43.28 & 25.25 & 11.22 & 0 \\
$\mathbf{5}$ & 59.07 & 38.25 & 27.50 & 20.31 & 15.02 & 10.86 & 7.47 & 4.61 & 2.15 & 0 \\
$\mathbf{1 0}$ & 26.15 & 17.64 & 12.92 & 9.69 & 7.25 & 5.29 & 3.67 & 2.28 & 1.07 & 0 \\
$\mathbf{1 5}$ & 16.76 & 11.44 & 8.44 & 6.36 & 4.78 & 3.50 & 2.43 & 1.51 & 0.71 & 0 \\
$\mathbf{2 0}$ & 12.32 & 8.46 & 6.27 & 4.73 & 3.56 & 2.61 & 1.82 & 1.13 & 0.53 & 0
\end{tabular}

$i=0.05 \quad c$

$\begin{array}{lllllllllll}\mathrm{t} & 0.1 & 0.2 & 0.3 & 0.4 & 0.5 & 0.6 & 0.7 & 0.8 & 0.9 & 1\end{array}$

$\begin{array}{lllllllllll}1 & 945 & 420 & 245 & 157.5 & 105 & 70 & 45 & 26.25 & 11.67 & 0\end{array}$

$\begin{array}{lllllllllll}5 & 61.14 & 39.87 & 28.59 & 21.11 & 15.61 & 11.29 & 7.76 & 4.79 & 2.24 & 0\end{array}$

$\begin{array}{lllllllllll}10 & 27.19 & 18.33 & 13.43 & 10.06 & 7.54 & 5.50 & 3.81 & 2.37 & 1.11 & 0\end{array}$

$\begin{array}{lllllllllll}15 & 17.42 & 11.89 & 8.78 & 6.61 & 4.96 & 3.63 & 2.53 & 1.57 & 0.74 & 0\end{array}$

$\begin{array}{lllllllllll}20 & 12.28 & 8.80 & 6.51 & 4.92 & 3.70 & 2.72 & 1.89 & 1.18 & 0.55 & 0\end{array}$

Note that $\mathrm{i}$ is the risk free interest rate, $\mathrm{t}$ represents years and $\mathrm{c}$ is the ration of certainty equivalent and expected cash flow in period $t$ (see equation 5). 
Table 2. Risk loading $v$ for different levels of $i$ and $d$.

\begin{tabular}{llllll}
\hline $\mathbf{d}$ & $\mathbf{i = 0 . 0 1}$ & $\mathbf{i = 0 . 0 2}$ & $\mathbf{i}=\mathbf{0 . 0 3}$ & $\mathbf{i = 0 . 0 4}$ & $\mathbf{i = 0 . 0 5}$ \\
$\mathbf{0 . 0 1}$ & 1.00 & 1.00 & 1.00 & 1.10 & 1.10 \\
$\mathbf{0 . 0 2}$ & 2.10 & 2.10 & 2.10 & 2.10 & 2.10 \\
$\mathbf{0 . 0 3}$ & 3.10 & 3.20 & 3.20 & 3.20 & 3.20 \\
$\mathbf{0 . 0 4}$ & 4.20 & 4.30 & 4.30 & 4.30 & 4.40 \\
$\mathbf{0 . 0 5}$ & 5.30 & 5.40 & 5.40 & 5.50 & 5.50 \\
$\mathbf{0 . 0 6}$ & 6.40 & 6.50 & 6.60 & 6.60 & 6.70 \\
$\mathbf{0 . 0 7}$ & 7.60 & 7.70 & 7.80 & 7.80 & 7.90 \\
$\mathbf{0 . 0 8}$ & 8.80 & 8.90 & 9.00 & 9.00 & 9.10 \\
$\mathbf{0 . 0 9}$ & 10.00 & 10.10 & 10.20 & 10.30 & 10.40 \\
$\mathbf{0 . 1 0}$ & 11.20 & 11.30 & 11.40 & 11.60 & 11.70 \\
\hline
\end{tabular}

Note that $i$ is the risk free interest rate and $d$ is the (negative) annual growth rate of $c$, the ratio of certainty equivalents over expected cash flows (see equation 9).

Table 3. Characteristics of cash flow distributions and risk premia (in $€$ ha $^{-1}$ )

\begin{tabular}{|c|c|c|c|c|c|c|c|}
\hline \multirow{2}{*}{$E\left(\pi_{t}\right)$} & $t=0$ & $t=5$ & $t=10$ & $t=15$ & $t=20$ & $t=25$ & $t=30$ \\
\hline & -2857 & 823 & 1221 & 1187 & 1176 & 1172 & -229 \\
\hline \multicolumn{8}{|l|}{$\operatorname{Var}\left(\pi_{t}\right)$ (in $(€$} \\
\hline$\left.\left.h a^{-1}\right)^{2}\right)$ & 0 & 179900 & 520007 & 526708 & 527452 & 527534 & 527543 \\
\hline $\begin{array}{l}\text { Level of risk } \\
\text { aversion }\end{array}$ & \multicolumn{7}{|c|}{ Risk Premium } \\
\hline$r=0$ & 0 & 0 & 0 & 0 & 0 & 0 & 0 \\
\hline$r=0.001$ & 0 & 90 & 260 & 263 & 264 & 264 & 264 \\
\hline$r=0.002$ & 0 & 180 & 520 & 527 & 527 & 528 & 528 \\
\hline$r=0.003$ & 0 & 270 & 780 & 790 & 791 & 791 & 791 \\
\hline
\end{tabular}

Note that $\mathrm{t}$ represents years and $\mathrm{r}$ is the coefficient of absolute risk aversion.

Table 4. Levels of $c$ for different degrees of risk aversion.

\begin{tabular}{|c|c|c|c|c|c|c|c|}
\hline & $t=0$ & $t=5$ & $t=10$ & $t=15$ & $t=20$ & $t=25$ & $t=30$ \\
\hline$r=0$ & 1 & 1 & 1 & 1 & 1 & 1 & 1 \\
\hline$r=0.001$ & 1 & 0.89 & 0.79 & 0.78 & 0.78 & 0.77 & 2.15 \\
\hline$r=0.002$ & 1 & 0.78 & 0.57 & 0.56 & 0.55 & 0.55 & 3.31 \\
\hline
\end{tabular}


$r=0.003$

0.67

0.36

0.33

0.33

0.33

4.45

Note that $t$ represents years and $r$ is the coefficient of absolute risk aversion.

Table 5. Levels of the risk loading $v$ (in \%) for different degrees of risk aversion.

\begin{tabular}{cccccccc}
\hline & $\mathbf{t}=\mathbf{0}$ & $\mathbf{t}=\mathbf{5}$ & $\mathbf{t}=\mathbf{1 0}$ & $\mathbf{t}=\mathbf{1 5}$ & $\mathbf{t}=\mathbf{2 0}$ & $\mathbf{t}=\mathbf{2 5}$ & $\mathbf{t}=\mathbf{3 0}$ \\
$\boldsymbol{r}=\mathbf{0}$ & 0 & 0 & 0 & 0 & 0 & 0 & 0 \\
$\boldsymbol{r}=\mathbf{0 . 0 0 1}$ & 0 & 2.45 & 2.48 & 1.73 & 1.30 & 1.09 & -2.62 \\
$\boldsymbol{r}=\mathbf{0 . 0 0 2}$ & 0 & 5.29 & 6.01 & 4.09 & 3.15 & 2.51 & -4.06 \\
$\boldsymbol{r}=\mathbf{0 . 0 0 3}$ & 0 & 8.66 & 11.17 & 7.97 & 5.92 & 4.71 & -5.04 \\
\hline
\end{tabular}

Note that $t$ represents years and $r$ is the coefficient of absolute risk aversion.

Table 6. Discounted cash flows and NPVs (in $€$ ha $^{-1}$ ) for different levels of risk aversion.

\begin{tabular}{|c|c|c|c|c|c|c|c|c|}
\hline & $t=0$ & $t=5$ & $\mathrm{t}=10$ & $t=15$ & $\mathrm{t}=20$ & $\mathrm{t}=25$ & $\mathbf{t}=\mathbf{3 0}$ & NPV \\
\hline$E\left(\pi_{t}\right)$ & -2857 & 823 & 1221 & 1187 & 1176 & 1172 & -229 & ---- \\
\hline \multicolumn{9}{|c|}{ Discounted Cash flows based on the time variant risk loadings in Table 5} \\
\hline$r=0$ & -2857 & 380 & 731 & 625 & 530 & 441 & -72 & -222 \\
\hline$r=0.001$ & -2857 & 340 & 583 & 494 & 421 & 347 & -160 & -832 \\
\hline$r=0.002$ & -2857 & 298 & 420 & 355 & 297 & 248 & -246 & -1485 \\
\hline$r=0.003$ & -2857 & 256 & 265 & 209 & 178 & 149 & -330 & -2130 \\
\hline \multicolumn{9}{|c|}{ Discounted Cash flows based on time invariant levels of $v$} \\
\hline$v=0.01$ & -2857 & 364 & 670 & 548 & 445 & 355 & -56 & -530 \\
\hline$v=0.05$ & -2857 & 302 & 461 & 313 & 211 & 139 & -18 & -1450 \\
\hline$v=0.10$ & -2857 & 241 & 294 & 159 & 86 & 45 & -5 & -2036 \\
\hline
\end{tabular}

Note that $\mathrm{t}$ represents years, $\mathrm{r}$ is the coefficient of absolute risk aversion and $v$ is the risk loading. 